\title{
Direct Shoot Organogenesis and Clonal Fidelity Confirmation of Tongkat Ali (Eurycoma longifolia) using Molecular Markers
}

\author{
Annor Gebril Annour Alttaher ${ }^{1}$, Zetty Norhana Balia Yusof ${ }^{1}$ and Noor Azmi Shaharuddin ${ }^{1,2 *}$ \\ ${ }^{1}$ Department of Biochemistry, Faculty of Biotechnology and Biomolecular Sciences, Universiti Putra Malaysia, Serdang \\ 43400, Malaysia \\ ${ }^{2}$ Institute of Tropical Agriculture and Food Security, Universiti Putra Malaysia, Serdang 43400, Malaysia \\ *For correspondence: noorazmi@upm.edu.my; nour732005@gmail.com \\ Received 26 June 2020; Accepted 04 January 2021; Published 10 June 2021
}

\begin{abstract}
Eurycoma longifolia is a medicinally potent plant found in the tropical forest of South-East Asia. Every part of the plant, especially the root is traditionally used as an aphrodisiac, anticancer and anti-inflammatory. E. longifolia is conventionally propagated by seeds but with low germination rate and efficiency. This has made an in vitro propagation of E. longifolia a desirable alternative. Hence, this study reports an effective method of direct organogenesis of shoot. In vitro seedling's leaves were cultured on Murashige and Skoog (MS) medium containing $1.0 \mathrm{mg} \mathrm{L}^{-1}$ 6-benzylaminopurine (BAP), producing $1.8 \pm 0.5$ shoots per leaf with a regeneration frequency of $68.2 \%$. The shoot buds were directly formed from leaves without intermediate callus formation. To obtain complete plantlets, the shoots were in vitro rooted with an average number of $4.2 \pm 0.4$ roots per shoot in half-strength MS (1/2MS) medium supplemented with $0.5 \mathrm{mg} \mathrm{L}^{-1}$ indole-3-butyric acid (IBA). Regenerated plantlets were successfully acclimatized to field conditions with an $85 \%$ survival rate. Genetic fidelity of the micropropagated plantlets was evaluated using Simple Sequence Repeat (SSR) and Inter Simple Sequence Repeat (ISSR) analysis. The results showed that the monomorphic banding patterns of in vitro raised plantlets and their mother plant were similar, confirming its homogeneity and the reliability of the multiplication system. (C) 2021 Friends Science Publishers
\end{abstract}

Keywords: Clonal fidelity; Eurycoma longifolia; Leaf explant; Shoot regeneration; SSR and ISSR

\section{Introduction}

Eurycoma longifolia Jack belongs to the family Simaroubaceae. It is one of the medicinal plants that has become medically targeted by local communities due to its aphrodisiac properties. E. longifolia is commonly found in the tropical forest of South-East Asia and is known by its vernacular name 'Tongkat Ali' in Malaysia (Alsarhan et al. 2014). Due to its diverse medicinal values, every part of the plant, especially the root is traditionally used as medicine (Yahya et al. 2015). Studies have revealed that the root extracts of $E$. longifolia have antimalarial, cytotoxic, aphrodisiac, antioxidant, anti-tumor, anti-inflammatory, anti-pyretic, and anti-amoebic properties, and also it has been applied in the treatment of diverse conditions such as fatigue, impotence, loss of sexual desire, high blood pressure and fever (Rehman et al. 2016).

E. longifolia is commonly propagated by seed germination. Like other woody plants, the proliferation of $E$. longifolia through seed germination is difficult due to the slow growth and the unreliability flowering habit. The seeds are produced once a year and have low rates of germination and the seeds take a long time to germinate (Danial et al. 2011). The roots of E. Longifolia that need 4-7 years to be harvested have further compounded the problem. Therefore, the conventional root production is time-consuming and depending on the harvesting season (Lulu et al. 2015).

Tissue culture technique provides an alternative solution for mass production of E. longifolia. Somatic embryogenesis and organogenesis are the most common techniques used for plant micropropagation and genetic transformation (Danial et al. 2011; Duncan 2011; Sidorov 2013). By using direct regeneration method, shoots and roots could be developed directly from an explant (Ayob et al. 2013; Raju et al. 2015). Leaf and cotyledon are one of the most desirable explants that are commonly used for in vitro regeneration due to their ability to preserve the genetic homozygosity (Huang et al. 2014; Islam and Bhattacharjee 2015).

Although a great number of researches have been done on E. longifolia, micropropagation studies are still scarce and insufficient. Hussein et al. (2005a) successfully regenerated shoots from cotyledon explant of $E$. longifolia through indirect somatic embryogenesis. Mahmood et al. (2010) 
then reported optimizing suitable auxin types and concentrations for induction of callus from different explants of $E$. longifolia. In addition, concentrations of different types of auxins have been reported in inducing adventitious roots from $E$. longifolia leaf explant (Hussein et al. 2012). By using cotyledon as an explant, Rodziah and Madihah (2015) successfully produced a high-frequency somatic embryo directly in a short time. More recently, an alternative system of temporary immersion (RITA) has been reported by Mohd et al. (2017) for proliferation somatic embryos derived from cotyledons of $E$. longifolia seeds. However, the direct formation of shoot buds of E. longifolia plant through the organogenesis is not still investigated well.

In general, indirect regeneration of plantlets through the callus formation is considered to be unreliable in the propagation of identical clones, while the regeneration of plantlets through the direct organogenesis or somatic embryogenesis have been reported to be genetically uniform. However, the possibility of somaclonal variations could not be ruled out completely (Krishna et al. 2016). Thus, micropropagated plantlets derived from long living woody plants should be early assessed for their genetic fidelity (Rohela et al. 2019).

Several DNA-based molecular markers have been used to assess the genetic fidelity in micropropagated plants. SSRs for example, are widely used markers due to their desirable characteristics, such as co-dominant inheritance nature, high reproducibility, high abundance in organisms, the enormous extent of allelic diversity, and strong discriminatory power (Kalia et al. 2011; Andeden et al. 2015). However, the major disadvantage of using SSR markers is the DNA primers are expensive and require plenty of time for development (Wang et al. 2011; Vieira et al. 2016). ISSRs are suitable alternative markers to the SSR markers since microsatellite markers are species-specific. ISSR is more efficient in detecting genetic variations in regenerated plants such as Cocos nucifera L. (Bandupriya et al. 2017) and grapevine cv. (Nookaraju and Agrawal 2012). The ISSR can amplify an SSR motif occurring in specific regions of a genome ( $\mathrm{Ng}$ and $\mathrm{Tan} 2015)$.

This current study aimed to develop an efficient protocol for direct shoot regeneration from leaf explants of E. longifolia. One of the major requirements of micropropagation was a production of uniform plantlets, but sometimes this could be hampered due to genetic variability. Therefore, in this research, SSR and ISSR were used to evaluate the clonal fidelity among the micropropagated plantlets of E. longifolia and their mother plants.

\section{Materials and Methods}

\section{Plant materials and explant preparation}

The plant used in this study was provided by Institute of Bioscience, University Putra Malaysia (UPM). All experimental procedures were carried out at Plant
Biochemistry and Biotechnology Laboratory of Biochemistry Department at UPM. In vitro seed germination was carried out to ensure aseptic growth conditions of seedlings as a source of leaf explants (Fig. 1). Matured ripe dark-red fruits of E. longifolia were washed with Teepol and rinsed for 30 min under running tap water. The epicarp and mesocarp of fruits were manually removed. The surface-sterilization of seeds was carried out in a laminar-flow hood based on the procedure explained by Mahmood et al. (2010) as follows: seeds soaked in $70 \%$ $(\mathrm{v} / \mathrm{v})$ ethanol for $5 \mathrm{~min}$; and then submersed for $20 \mathrm{~min}$ in $20 \%$ (v/v) Clorox ${ }^{\circledR}$ plus two drops of Tween-20. Then the seeds were rinsed 5 times with sterile distilled water. After sterilization, the seed coat was removed to hasten the rate of germination and help to avoid some phenolic compounds that naturally released in culture media from the seed coat. Cotyledons and embryos were aseptically placed on fullstrength Murashige and Skoog (1962) (MS) medium for 2 to 3 weeks until embryos germinated and seedlings had well-developed leaves.

\section{Culture medium and conditions}

All experiments were conducted using MS medium supplemented with various concentrations of plant growth regulators (PGRs) and $30 \mathrm{~g} \mathrm{~L}^{-1}$ sucrose. The $\mathrm{pH}$ of culture medium was adjusted to 5.8 using $1 \mathrm{~N} \mathrm{HCl}$ or $1 \mathrm{~N} \mathrm{NaOH}$, then $2.45 \mathrm{~g} \mathrm{~L}^{-1}$ of Gelrite added to the medium before autoclaving at $121^{\circ} \mathrm{C}$ and $1.06 \mathrm{~kg} \mathrm{~cm}^{-2}$ pressure for $20 \mathrm{~min}$. All cultures were maintained in a growth room at $25 \pm 2^{\circ} \mathrm{C}$ in photoperiod of $16 \mathrm{~h}$ light and $8 \mathrm{~h}$ dark with $35 \mu \mathrm{mol}$ $\mathrm{m}^{-2} \mathrm{~s}^{-1}$ photon flux density obtained from white bulbs of fluorescent. Relative humidity was maintained at $60 \%$.

\section{Direct shoot organogenesis}

For direct regeneration of shoot, leaf explants were excised from the 3-week-old aseptic in vitro-grown seedlings. Leaf segments $\left(0.5 \mathrm{~cm}^{2}\right)$ were inoculated in $100 \mathrm{~mL}$ conical flasks containing $30 \mathrm{~mL}$ of MS medium supplemented with various cytokinins such as 6-benzylaminopurine (BAP) and kinetin (KIN) at concentrations $(0.5,1.0,1.5,2.0$ and $2.5 \mathrm{mg}$ $\mathrm{L}^{-1}$ ) and Thidiazuron (TDZ) at concentrations of 0.2, 0.5, 1.0 and $2.0 \mathrm{mg} \mathrm{L}^{-1}$. The leaf segments were cut transversely across the midrib and placed horizontally on the culture medium with their abaxial side in contact with the surface of the medium (Singh et al. 2013). Shoot cultures were subcultured every 4-week interval onto a fresh medium containing the same concentrations of cytokinins. The data on percentage of shoot regeneration, shoot number per laef and length of shoot were recorded every week. All experiments were repeated three times with three replicates for each treatment.

\section{In vitro rooting and acclimatization}

To obtain a complete plantlet, the in vitro regenerated shoots 

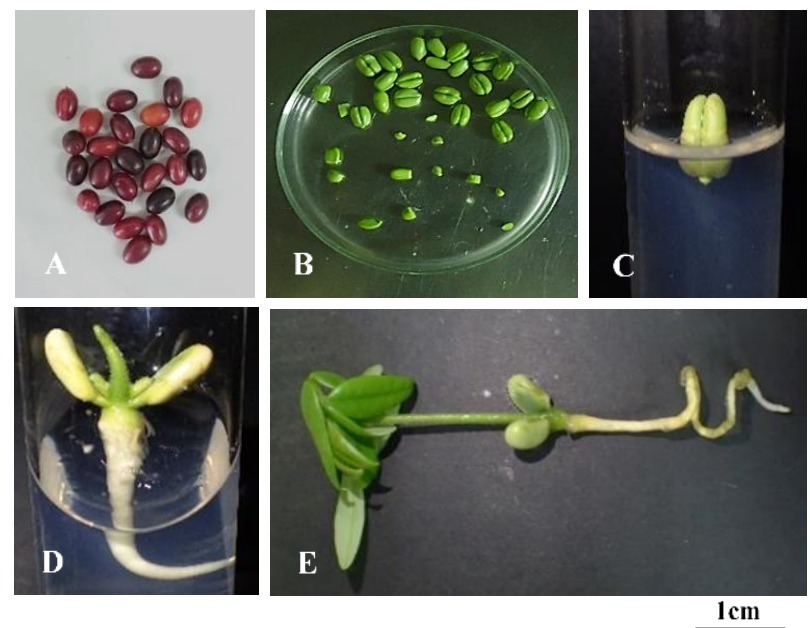

Fig. 1: In vitro germination of Eurycoma longifolia seeds (A) Matured ripe dark-red fruits. (B) Isolated cotyledons and embryos ready for inoculation (C) Cotyledons and embryo placed on germination media (D) Germination of seed (E) In vitro seedling

(2.5 $-4.5 \mathrm{~cm}$ in length) were individually separated from the leaf explants and cultured the rooting medium under aseptic conditions. The rooting medium comprises $1 / 2 \mathrm{MS}$ medium with auxins such as indole-3-butyric acid (IBA) or naphthaleneacetic acid (NAA) at concentrations of $0.2,0.5$, 1.0 and $2.0 \mathrm{mg} \mathrm{L}^{-1}$. The observations on percentage of root induction, the roots number per shoot and length of the roots were recorded after two weeks of culturing on the rooting medium. Acclimatization was carried out as follows: regenerated plantlets that had vigorous shoots with a welldeveloped root system were gently removed from the culture medium and washed carefully with distilled water to eliminate the traces of nutrient medium from the surfaces of roots. Then the plantlets were potted in $7.5 \mathrm{~cm}$ plastic pots containing sterilized jiffy-7 medium. In order to maintain a high percentage of humidity around the plantlets, the plantlets were watered and covered with transparent polyethylene bags. After that, the plantlets were kept in a growth room in $8 \mathrm{~h}$ dark and $16 \mathrm{~h}$ light photoperiod at $25 \pm$ $2^{\circ} \mathrm{C}$ for an initial two weeks. After two weeks the humidity around the plantlets was gradually reduced by puncturing the polyethylene bags with small holes. Finally, the polyethylene bags were removed and plantlets were shifted to big plastic $18 \mathrm{~cm}$-pots containing garden soil. These plantlets were then kept under natural daylight conditions at the greenhouse for normal growth.

\section{Analysis of genetic fidelity}

The genetic homogeneity of the in vitro micropropagated plantlets was determined using SSR and ISSR markers. Genomic DNA of the plantlets and mother plants was extracted from fresh leaves $(200 \mathrm{mg})$ using modified cetyl trimethyl ammonium bromide (CTAB) method as described by Rai et al. (2012). The genomic DNA quantity and purity were determined by spectrophotometric analyses and agarose gel electrophoresis. Only genomic DNA with A260/280 nm ratio of 1.6 to 2.0 was selected and stored to be used for the following analyses.

The PCR reactions were performed in a total of $25 \mu \mathrm{L}$ volumes using Thermal cycler (Techne TC512, U.K.) based on the PCR program reported by Tnah et al. (2011) with an initial denaturation $\left(94^{\circ} \mathrm{C}\right)$ for $3 \mathrm{~min}$, followed by 35 cycles of denaturation at $94^{\circ} \mathrm{C}$ for $1 \mathrm{~min}$, then annealing for $1 \mathrm{~min}$ and extension at $72^{\circ} \mathrm{C}$ for $1 \mathrm{~min}$ and final extension at $72^{\circ} \mathrm{C}$ for $7 \mathrm{~min}$. The temperature of annealing was set at $2^{\circ} \mathrm{C}$ below the melting temperature of each primer sequence. The PCR amplification product was performed in three independent reactions for each primer set to confirm the reproducibility of the results. All positive and negative controls (reaction without DNA template) were included in each set of the PCR reactions to account for possible contamination. The amplification products were resolved on $1.5 \%(\mathrm{w} / \mathrm{v})$ agarose gel in $1 \times \mathrm{TAE}$ buffer and ran at 70 volts for an hour. All gels were stained with $0.25 \mu \mathrm{g} / \mu \mathrm{L}$ ethidium bromide. DNA fragments were visualized under ultraviolet light and photographed using Gel Logic-212 PRO Imaging software (Carestream, New York, U.S.A.). ExcelBand ${ }^{\mathrm{TM}}$ 100 base pairs DNA ladder (SMOBIO) was employed to estimate the size of the amplicons.

\section{Statistical analysis}

All experiments were statistically analysed based on a complete randomized design. MS medium free plant growth regulators served as a control for each analysis. The data obtained were subjected to one-way analysis of variance) to examine whether they were statistically significantly different from each other or not using Minitab software (version 16, Minitab Inc., State College, PA, U.S.A.). Means were subjected to Tukey's test $(P \leq 0.05)$ and the results were expressed as means \pm standard errors (ES). To test the primer reproducibility of amplification, all samples were run at least twice in different gels. The data recorded as discrete variables: 0 was recorded for the absence band and 1 for the presence band. Only reproducible and dense bands were scored and considered for further analysis.

\section{Results}

\section{Direct shoot organogenesis}

Successful induction of shoot buds was achieved by using leaves as explants (Fig. 2). After 8 weeks of culturing, induction of shoot buds were achieved from in vitro seedling leaves through the direct organogenesis. MS medium supplied with various cytokinins (BAP, KIN and TDZ) were applied to investigate their effect on shoot bud induction from the leaf explants. Our result shows that BAP at $1.0 \mathrm{mga}$ $\mathrm{L}^{-1}$ produced the highest frequency of shoot bud induction 


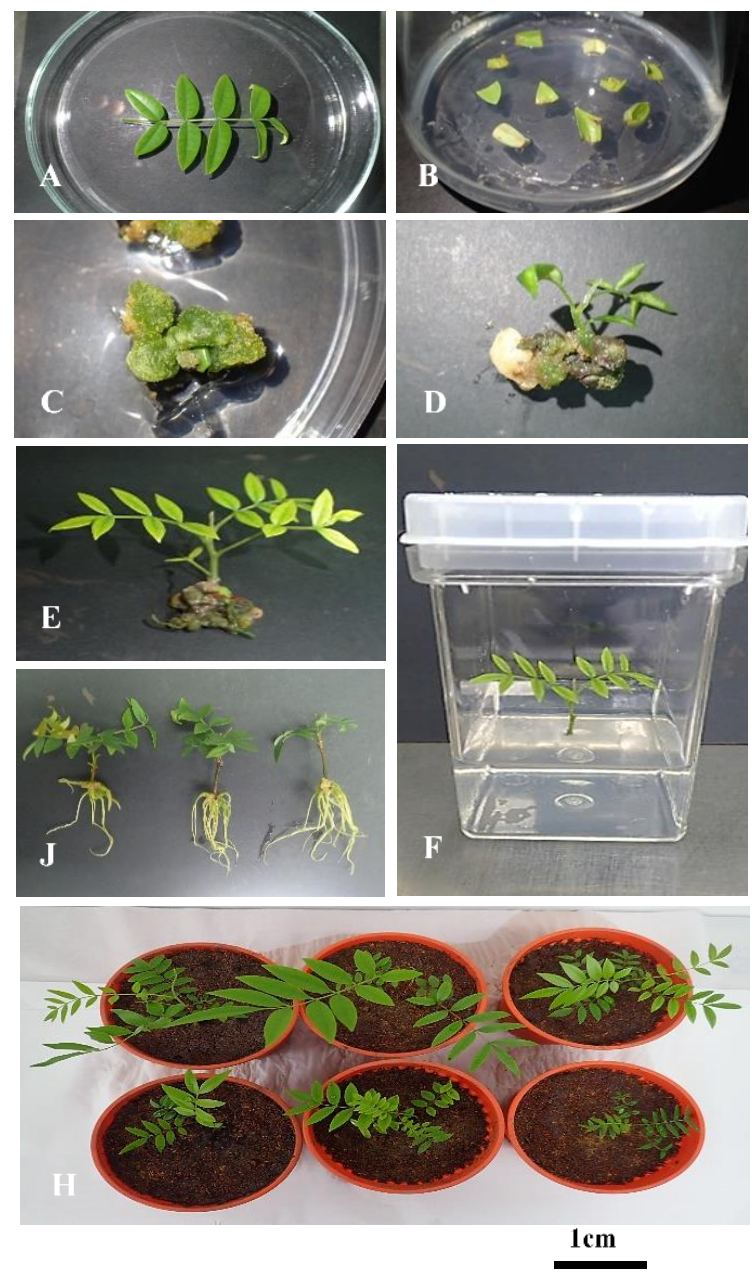

Fig. 2: Direct adventitious shoot from leaf explants of Eurycoma longifolia. (A) Leaf explants from in vitro seedling; (B) Leaflet segments cultured on shoot induction media; (C) Initiation of shoot buds; (D, E) Shoot regeneration from leaf; (F, J) In vitro rooting of shoot; $(\mathbf{H})$ Establishment of plants in the soil

(68.2\%) as compared to KIN and TDZ (Table 1). The maximum mean of shoot number $(1.8 \pm 0.5$ shoots per laef $)$ and shoot length $(2.8 \pm 0.6 \mathrm{~cm})$ were also observed on MS added with $1.0 \mathrm{mg} \mathrm{L}^{-1}$ of the BAP. The shoot bud induction was observed on the adaxial surface of the leaf explants. The shoot buds were initiated as a small group of meristematic cells on the surface of leaf explants. Whereupon, these cells subsequently developed into an adventitious bud within 6 to 8 weeks of culture, then it continued to form shoots from leaf explants in the following weeks (Fig. 2).

\section{In vitro rooting and plantlets acclimatization}

Elongated shoots $(2.5-4.5 \mathrm{~cm}$ in height $)$ were excised from the leaf explants and inoculated into the rooting medium to evaluate their ability to form roots. IBA and NAA with various concentrations were added to the $1 / 2 \mathrm{MS}$ medium for root induction from regenerated shoots. Although the roots were observed on $1 / 2 \mathrm{MS}$ medium without auxins, the presence of auxins had encouraged the shoots to induce a higher number of roots. As shown in Table 2, out of four concentrations of IBA and NAA tested, $0.5 \mathrm{mg} \mathrm{L}^{-1}$ of IBA has proven to be best for rooting, which represents the highest frequency of root formation $(90.2 \%)$. Moreover, the root length was the longest $(5.1 \pm 0.3 \mathrm{~cm})$ and the maximum number of roots $(4.2 \pm 0.4)$ was also achieved at $0.5 \mathrm{mg} \mathrm{L}^{-1}$ of IBA. Similarly, IBA was the best auxin for root induction from internode explants of Asteracantha longifolia (Kumar and Nandi 2015) and Strobilanthes tonkinensis (Srikun 2017). However, the lowest mean roots number per shoot $(0.4 \pm 0.1)$ was observed in the treatment of $1 / 2 \mathrm{MS}$ with 0.2 $\mathrm{mg} \mathrm{L}^{-1}$ NAA after six weeks of incubation. There was a significant difference between $0.5 \mathrm{mg} \mathrm{L}^{-1}$ IBA and $1.0 \mathrm{mg}$ $\mathrm{L}^{-1}$ IBA in the mean number of roots produced.

In this current study, regenerated plantlets that had a vigorous root system was selected for the acclimatization stage. These plantlets were washed with autoclaved distilled water to remove all adhered medium from their roots. Nutrient medium must be removed from the roots because it might be an adequate environment for growing microorganisms that would cause rotting of the roots. It was observed that plantlets that have a developed root system before being transferred to soil, seemed to be wellestablished during the acclimatization stage.

\section{Analysis of genetic fidelity}

Out of the 12 SSR primer pairs screened, only 7 SSR primer pairs had generated a single scorable band per primer. These SSR primers generated 7 amplicons with sizes ranging from 100 to $300 \mathrm{bp}$ (Table 3.). The bands sizes were almost the same in each primer within the range as previously described by Tnah et al. (2011). On the other hand, preliminary screening of ISSR primers showed that, a total of 8 ISSR primers could amplify reproducible and scorable bands. These 8 primers gave 27 bands with sizes ranging from 300 to $1000 \mathrm{bp}$, and the number of bands differed from 1 band with UBC-851 to 6 bands with UBC-811 in average of 3.4 bands per primer (Table 4). Fig. 3 shows the pattern of amplification obtained from ISSR primer UBC-807 and SSR primer Elo 066. Overall, amplification products obtained by SSR and ISSR primers showed that both micropropagated plantlets and the mother plant exhibited a monomorphic banding pattern. This pattern of banding confirms the genetic homogeneity of the clones. Table 5 shows a summary of SSR and ISSR amplified products obtained from nine samples of E. longifolia. As shown in Table 5, seven SSR primers reproduced 7 bands with 1.0 bands per primer in average. However, in ISSR 8 primers resulted in one to six of scorable bands regenerated a total of 27 amplicons (3.4 bands on average). These results confirmed that the in vitro raised plantlets of E. longifolia could remain free from somaclonal variations and true-totype nature over a culture period. 
Clonal Fidelity of in vitro Propagated Tongkat Ali / Intl J Agric Biol, Vol 26, No 1, 2021

Table 1: Effect of different concentrations of cytokinins in MS medium on shoot bud regeneration from leaf explants of Eurycoma longifolia

\begin{tabular}{lllll}
\hline Cytokinins & Concentration $\left(\mathrm{mg} \mathrm{L}^{-1}\right)$ & Regeneration frequency $(\%)$ & No. of shoots/explant $(\mathrm{mean} \pm \mathrm{SE})$ & Shoot length $(\mathrm{cm})(\mathrm{mean} \pm \mathrm{SE})$ \\
\hline Control & 0.0 & 0.0 & 0.0 & 0.0 \\
& 0.5 & 48.3 & $0.3 \pm 0.1 \mathrm{ef}$ & $1.6 \pm 0.4 \mathrm{~cd}$ \\
$\mathrm{BAP}$ & 1.0 & 68.2 & $1.8 \pm 0.5 \mathrm{a}$ & $2.8 \pm 0.6 \mathrm{a}$ \\
& 1.5 & 63.7 & $1.2 \pm 0.4 \mathrm{~b}$ & $2.1 \pm 0.5 \mathrm{~b}$ \\
& 2.0 & 51.3 & $0.9 \pm 0.1 \mathrm{c}$ & $2.0 \pm 0.1 \mathrm{~b}$ \\
& 2.5 & 41.4 & $0.5 \pm 0.1 \mathrm{de}$ & $1.4 \pm 0.5 \mathrm{~d}$ \\
& 0.1 & 38.4 & $0.5 \pm 0.1 \mathrm{de}$ & $0.4 \pm 0.1 \mathrm{fg}$ \\
$\mathrm{TDZ}$ & 0.2 & 44.0 & $0.8 \pm 0.2 \mathrm{c}$ & $0.9 \pm 0.1 \mathrm{e}$ \\
& 0.5 & 56.8 & $0.4 \pm 0.1 \mathrm{e}$ & $0.7 \pm 0.1 \mathrm{c}$ \\
& 1.0 & 28.9 & $0.6 \pm 0.2 \mathrm{~d}$ & $0.5 \pm 0.2 \mathrm{f}$ \\
& 1.5 & 11.6 & $0.6 \pm 0.1 \mathrm{~d}$ & $0.3 \pm 0.1 \mathrm{~g}$ \\
Kin & 0.5 & 21.3 & $0.4 \pm 0.1 \mathrm{e}$ & $0.9 \pm 0.2 \mathrm{e}$ \\
& 1.0 & 33.1 & $1.9 \pm 0.5 \mathrm{a}$ & $1.5 \pm 0.4 \mathrm{~cd}$ \\
& 1.5 & 49.7 & $1.3 \pm 0.4 \mathrm{~b}$ & $0.8 \pm 0.3 \mathrm{e}$ \\
& 2.0 & 38.4 & $0.7 \pm 0.1 \mathrm{~cd}$ & $0.3 \pm 0.1 \mathrm{~g}$
\end{tabular}

*Means within a column that do not share a letter are significantly different at $P \leq 0.05$ using Tukey's test

Table 2: Effect of different concentrations of auxins in $1 / 2 \mathrm{MS}$ solid medium on in vitro root induction from shoot regenerated from the leaf and cotyledon explants of Eurycoma longifolia

\begin{tabular}{lllll}
\hline Auxins & Concentrations $\left(\mathrm{mg} \mathrm{L}^{-1}\right)$ & Regeneration frequency $(\%)$ & No. of roots/shoot $(\mathrm{mean} \pm \mathrm{SE})$ & Root length $(\mathrm{cm})(\mathrm{mean} \pm \mathrm{SE})$ \\
\hline Control & 00 & 18.0 & $0.3 \pm 0.1 \mathrm{e}$ & $0.8 \pm 0.2 \mathrm{c}$ \\
& 0.2 & 35.3 & $0.8 \pm 0.3 \mathrm{~d}$ & $1.2 \pm 0.3 \mathrm{c}$ \\
& 0.5 & 90.2 & $4.2 \pm 0.4 \mathrm{a}$ & $5.1 \pm 0.3 \mathrm{a}$ \\
$\mathrm{IBA}$ & 1.0 & 56.3 & $2.3 \pm 0.6 \mathrm{~b}$ & $2.8 \pm 0.1 \mathrm{~b}$ \\
& 2.0 & 30.1 & $1.9 \pm 0.4 \mathrm{~b}$ & $2.2 \pm 0.2 \mathrm{~b}$ \\
& 0.2 & 15.1 & $0.4 \pm 0.1 \mathrm{e}$ & $0.6 \pm 0.1 \mathrm{c}$ \\
NAA & 0.5 & 23.2 & $1.0 \pm 0.4 \mathrm{c}$ & $0.9 \pm 0.3 \mathrm{c}$ \\
& 1.0 & 30.3 & $1.4 \pm 0.3 \mathrm{c}$ & $2.0 \pm 0.3 \mathrm{~b}$ \\
& 2.0 & 19.1 & $0.7 \pm 0.2 \mathrm{~d}$ & $1.2 \pm 0.2 \mathrm{c}$
\end{tabular}

Table 3: The number and size of the amplified fragments generated by SSR primers in Eurycoma longifolia

\begin{tabular}{lllll}
\hline Primer code & Annealing temperature $\left({ }^{\circ} \mathrm{C}\right)$ & Number of scorable bands/primer & Total number of bands amplified & Range of amplification (bp) \\
\hline Elo 002 & 55 & 1 & 9 & $200-300$ \\
Elo 026 & 45 & 1 & 9 & $200-300$ \\
Elo 066 & 55 & 1 & 9 & $200-300$ \\
Elo 085 & 55 & 1 & 9 & $200-300$ \\
Elo 099 & 45 & 1 & 9 & $100-200$ \\
Elo 104 & 45 & 1 & 9 & $200-300$ \\
Elo 112 & 45 & 1 & 9 & $100-200$ \\
\hline
\end{tabular}

Table 4: The number and size of the amplified fragments generated by ISSR primers in Eurycoma longifolia

\begin{tabular}{lllll}
\hline Primer code & Annealing temperature $\left({ }^{\circ} \mathrm{C}\right)$ & Number of scorable bands/primer & Total number of Bands amplified & Range of amplification (bp) \\
\hline UBC-807 & 40 & 3 & 27 & $300-600$ \\
UBC-808 & 45 & 3 & 27 & $400-900$ \\
UBC-809 & 40 & 5 & 45 & $300-900$ \\
UBC-811 & 40 & 6 & 54 & $400-1000$ \\
UBC-812 & 40 & 3 & 27 & $400-700$ \\
UBC-835 & 43 & 4 & 36 & $300-600$ \\
UBC-840 & 40 & 2 & 18 & $400-600$ \\
UBC-851 & 43 & 1 & 9 & $600-700$ \\
\hline
\end{tabular}

Table 5: Summary of SSR and ISSR amplified products from nine samples of Eurycoma longifolia

\begin{tabular}{llll}
\hline Description & SSR & ISSR & SSR + ISSR \\
\hline Total bands scored & 7 & 27 & 34 \\
Number of monomorphic bands & 7 & 27 & 34 \\
Number of polymorphic bands & 0 & 0 & 0 \\
Number of primers used & 7 & 8 & 15 \\
Average number of fragments per primer & 1.0 & 3.4 & 4.4 \\
Size range of amplified fragments (bp) & $100-300$ & $300-1000$ \\
\hline
\end{tabular}



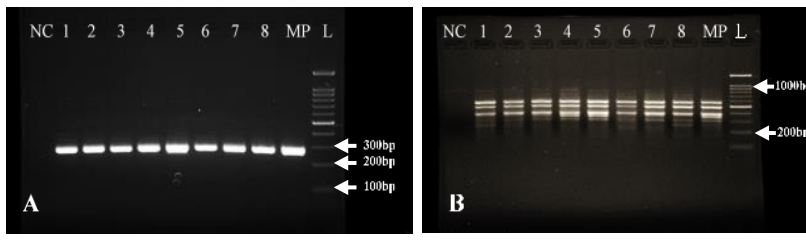

Fig. 3: DNA amplification obtained with A) SSR primer (Elo 066). B) ISSR primer (UBC807) Lane NC: Negative Control, Lanes 1 - 8: in vitro raised plants, Lane MP: Mother plant, Lane L: 100-bp ladder

\section{Discussion}

The direct shoot regeneration protocols could provide a potential technique that can be utilized in genetic transformation. In this study, shoot buds were induced from leaf explants. It has been reported that cytokinin concentration has an efficient effect on shoot organogenesis from explant. High concentrations of cytokinins have been reported to reduce the number of shoot buds and callus production (Khan et al. 2015). Contrarily, lower concentration of cytokinins in culture medium has been related to shoot bud proliferation from leaf explants (Singh et al. 2013; Kumlay and Ercisli 2015). As expected, by increasing BAP concentration, the frequency of shoot initiation, average number and length of shoots were decreased in the current study. On the other hand, TDZ induced the lowest number of shoot buds from leaf explants with all concentrations tested and these shoots seemed to be stunted. However, prolonged exposure of regenerated shoots to medium supplied with high concentrations of TDZ resulted in distortion and exhibited stunted growth of shoots (Dewir et al. 2018). The fasciation of the shoots or formation of stunted shoots on the medium contained TDZ, has been reported in several species of plants such Cassia sophera Linn (Parveen et al. 2010) and Vitex trifolia L (Ahmed and Anis 2012).

The rooting of in vitro regenerated shoots is an important step for the successful formation of the whole plantlets that can survive in ex vitro conditions (Toppo et al. 2012; Shekhawat et al. 2015). Auxins are generally subjected to be used for root induction, but they might prevent the continued growth of roots if they remain in the same rooting medium (Harahap et al. 2014). Shekhawat et al. (2014) reported that IBA is an auxin that plays a significant role in the induction of roots from regenerated shoots of Turnera ulmifolia. A study conducted on shoot tip explants of E. longifolia by Hussein et al. (2005b) has shown that 0.4 and $0.5 \mathrm{mg} \mathrm{L}^{-1}$ of IBA were suitable to induce roots from regenerated shoots. They also reported that NAA generated undesirable thick and short roots. Contrary to that, another study conducted by Hussein et al. (2012) found that NAA was more efficient in adventitious root induction from E. longifolia leaf explants. This is in agreement with this current study, which observed that the concentration of $0.5 \mathrm{mg} \mathrm{L}^{-1}$ IBA was the best for root induction in E. Longifolia plants. Besides, IBA induced vigorous roots without the formation of callus on the shoots. Kumar and Nandi (2015) reported a similar observation with the same concentration of auxin $\left(0.5 \mathrm{mg} \mathrm{L}^{-1} \mathrm{IBA}\right)$ in the $1 / 2 \mathrm{MS}$ medium for induction of root from Asteracantha longifolia. Micropropagated plantlets, which are developed in a controlled microenvironment might desiccate and die if they were directly placed at a low level of humidity or higher light level that is stressful as compared to in vitro conditions. Moreover, during the acclimatization process the plantlets have poor photosynthetic capability and the leaves act as a source of carbohydrates for the newly developing leaves. This poor photosynthetic capability could cause the deaths of some of the micropropagated plantlets (ChaariRkhis et al. 2015). Several studies have shown that the usage of $100 \%$ jiffy-7 was the suitable potting medium for the plantlets acclimatization (Yahya et al. 2015; Nabilah et al. 2017). After one month of acclimatization in the laboratory, the plants were transferred to the large pots containing garden soil for further growth and to be ready for transfer to the field. The plants were adapted to the field conditions with $85 \%$ of the survival percentage.

The genetic differences among in vitro plantlets usually occur as a result of the exposure of plant tissues to in vitro conditions. This difference could have a negative impact on application of tissue culture techniques in the conservation of important traits in plants (Bairu et al. 2011; Cruz-Martínez et al. 2017). For better results of genetic homogeneity analysis, it is always recommended to use more than one marker that can help to target different regions of the genome because in vitro propagation might provoke somaclonal variation in in vitro raised plantlets (Agarwal et al. 2015; Muthukumar et al. 2016). Two genetic markers (SSR and ISSR) were used in the current study due to their efficiency in the assessment of clonal fidelity and genetic diversity studies (Bairu et al. 2011; Kalia et al. 2011; Krishna et al. 2016). The use of SSR and ISSR in the evaluation of genetic homogeneity of in vitro propagated plants have been reported in many species of plants such as Alhagi maurorum (Agarwal et al. 2015); Simmondsia chinensis (Kumar and Reddy 2011); Salvadora persica L. (Kumari et al. 2017); Withania somnifera L. (Nayak et al. 2013); Grapevine cv. (Nookaraju and Agrawal 2012); Psidium guajava L. (Rai et al. 2012) and acid lime accessions (Sharafi et al. 2016).

\section{Conclusion}

In conclusion, this study reports an efficient plantlet regeneration system from leaf explants of E. longifolia via direct organogenesis. This is the first report on shoot induction from leaf explant. SSR and ISSR markers were utilized to validate the genetic homogeneity among the micropropagated plantlets. DNA fingerprints of micropropagated plantlets showed a monomorphic pattern 
similar to their mother plant, demonstrating the homogeneity of the in vitro raised plantlets. The regeneration protocol described here could be beneficial for the conservation of germplasm and mass production of $E$. longifolia plants with less risk of genetic variability.

\section{Acknowledgements}

The authors would like to thank the Biodiversity Unit at the Institute of Bioscience University Putra Malaysia for providing the plant material for this research. This research was funded by Putra Graduate Initiative (IPS) grant, Universiti Putra Malaysia.

\section{Author Contributions}

All the authors meet the essential criteria of the publication. AGAA performed the experiments and prepared the manuscript, ZNBY designed the experiments and NAS supervised the research work.

\section{Conflicts of Interest}

Authors have no conflict of interest with regards to this manuscript.

\section{Data Availability}

The data will be made available on fair request to the corresponding author.

\section{Ethics Approval}

Not applicable.

\section{References}

Agarwal T, AK Gupta, AK Patel, NS Shekhawat (2015). Micropropagation and validation of genetic homogeneity of Alhagi maurorum using SCoT, ISSR and RAPD markers. Plant Cell Tiss Org Cult 120:313-323

Ahmed MR, M Anis (2012). Role of TDZ in the quick regeneration of multiple shoots from nodal explant of Vitex trifolia L. - an important medicinal plant. Appl Biochem Biotechnol 168:957-966

Alsarhan A, N Sultana, A Al-Khatib, MRA Kadir (2014). Review on some Malaysian traditional medicinal plants with therapeutic properties. $J$ Basic Appl Sci 10:149-159

Andeden EE, FS Baloch, E Çakır, F Toklu, H Özkan (2015). Development, characterization and mapping of microsatellite markers for lentil (Lens culinaris Medik.). Plant Breed 134:589-598

Ayob Z, A Wagiran, AA Samad (2013). Potential of tissue cultured medicinal plants in Malaysia. J Teknol 62:111-117

Bairu MW, AO Aremu, JV Staden (2011). Somaclonal variation in plants: Causes and detection methods. Plant Growth Regul 63:147-173

Bandupriya HDD, WWMA Iroshini, SACN Perera, VRM Vidhanaarachchi, SC Fernando, ES Santha, TR Gunathilake (2017). Genetic fidelity testing using SSR marker assay confirms trueness to type of micropropagated coconut (Cocos nucifera L.) plantlets derived from unfertilized ovaries. Open Plant Sci J 11:46-54
Chaari-Rkhis A, M Maalej, A Chelli-Chaabouni, L Fki, N Drira (2015). Photosynthesis parameters during acclimatization of in vitro-grown olive plantlets. Photosynthetica 53:613-616

Cruz-Martínez V, OA Castellanos-Hernández, GJ Acevedo-Hernández, MI Torres-Morán, M Gutiérrez-Lomelí, D Ruvalcaba-Ruiz, F Zurita, A Rodríguez-Sahagún (2017). Genetic fidelity assessment in plants of Sechium edule regenerated via organogenesis. S Afr J Bot 112:118-122

Danial M, CL Keng, SSRS Alwi, S Subramaniam (2011). Seed histology of recalcitrant Eurycoma longifolia plants during germination and its beneficial attribute for hairy roots production. $J$ Med Plant Res 5:93-98

Dewir YH, Y Naidoo, JAT De Silva (2018). Thidiazuron-induced abnormalities in plant tissue cultures. Plant Cell Rep 37:1451-1470

Duncan DR (2011). Organogenesis and embryogenesis in plant genetic transformation. In: Historical technology developments in plant transformation, pp:46-54. Dan Y, DW Ow (Eds.) Bentham Science Publication Oak Park

Harahap F, R Poerwanto, SC Suharsono, S Rahayu (2014). In vitro growth and rooting of Mangosteen (Garcinia mangostana L.) on medium with different concentrations of plant growth regulator. Hayati $J$ Biosci 21:151-158

Huang H, J Li, K Ou Yang, XLP Zhao, B Liao, X Chen (2014). Direct adventitious shoot organogenesis and plant regeneration from cotyledon explants in Neolamarckia cadamba. Plant Biotechnol $J$ 31:115-121

Hussein S, APK Ling, TH Ng, R Ibrahim, KY Paek (2012). Adventitious roots induction of recalcitrant tropical woody plant Eurycoma longifolia. Romanian. Biotechnol Lett 17:7026-7035

Hussein S, R Ibrahim, ALP Kiong, NM Fadzillah, SK Daud (2005a). Micropropagation of Eurycoma longifolia Jack via formation of somatic embryogenesis. Asian J Plant Sci 4:472-485

Hussein S, R Ibrahim, ALP Kiong, AMF Nor, SK Daud (2005b). Multiple shoots formation of an important tropical medicinal plant, Eurycoma longifolia Jack. Plant Biotechnol J 22:349-351

Islam SM, B Bhattacharjee (2015). Plant regeneration through somatic embryogenesis from leaf and root explants of Rhynchostylis retusa (L.) Blume. Appl Biol Res 17:158-165

Kalia RK, KR Manoj, K Sanjay (2011). Microsatellite markers: An overview of the recent progress in plants. Euphytica 177:309-334

Khan N, M Ahmed, I Hafiz, N Abbasi, S Ejaz, M Anjum (2015) Optimizing the concentrations of plant growth regulators for in vitro shoot cultures, callus induction and shoot regeneration from calluses of grapes. Oeno One 49:37-45

Krishna H, M Alizadeh, D Singh, U Singh, N Chauhan, M Eftekhari, RK Sadh (2016). Somaclonal variations and their applications in horticultural crops improvement. 3 Biotech 6:1-18

Kumar MS, SC Nandi (2015). High frequency plant regeneration with histological analysis of organogenic callus from internode explants of Asteracantha longifolia Nees. J Genet Eng Biotechnol 13:31-37

Kumar N, MP Reddy (2011). In vitro plant propagation: A review. J For Environ Sci 27:61-72

Kumari S, K Yadav, N Singh (2017). Evaluation of genetic fidelity among micropropagated plants of Salvadora persica L. using DNA-based markers. Meta Gene 14:129-133

Kumlay AM, S Ercisli (2015). Callus induction, shoot proliferation and root regeneration of potato (Solanum tuberosum L.) stem node and leaf explants under long-day conditions. Biotechnol Biotechnol Equip 29:1075-1084

Lulu T, SY Park, R Ibrahim, KY Paek (2015). Production of biomass and bioactive compounds from adventitious roots by optimization of culturing conditions of Eurycoma longifolia in balloon-type bubble bioreactor system. J Biosci Bioeng 119:712-717

Mahmood M, R Normi, S Subramaniam (2010). Optimization of suitable auxin application in a recalcitrant woody forest plant of Eurycoma longifolia (Tongkat Ali) for callus induction. Afr J Biotechnol 9:8417-8428

Mohd NM, J Hafsah, Z daiya Dalila, A Nadiaiawati (2017). In vitro somatic embryos multiplication of Eurycoma longifolia jack using temporary immersion system RITA. Sains Malays 46:897-902 
Murashige T, F Skoog (1962). A revised medium for rapid growth and bio assays with tobacco tissue cultures. Physiol Plantarum 15:473-497

Muthukumar M, TS Kumar, MV Rao (2016). Organogenesis and evaluation of genetic homogeneity through SCoT and ISSR markers in Helicteres isora L., a medicinally important tree. $S$ Afr $J$ Bot 106:204-210

Nabilah S, F Fazwa, S Suhaila, N Norhayati, M Zaki, M Masitah (2017). Acclimatization of KFeFRIM01: A Superior Clone of Labisia pumila var. alata. Intl J Environ Agric Res 3:09-13

Nayak SA, S Kumar, K Satapathy, A Moharana, B Behera, DP Barik, L Acharya, PK Mohapatra, PK Jena, SK Naik (2013). In vitro plant regeneration from cotyledonary nodes of Withania somnifera (L.) Dunal and assessment of clonal fidelity using RAPD and ISSR markers. Acta Physiol Plantarum 35:195-203

$\mathrm{Ng} \mathrm{WL}$, SG Tan (2015). Inter-simple sequence repeat (ISSR) markers: Are we doing it right. ASM Sci J 9:30-39

Nookaraju A, DC Agrawal (2012). Genetic homogeneity of in vitro raised plants of grapevine cv. Crimson Seedless revealed by ISSR and microsatellite markers. $S$ Afr J Bot 78:302-306

Parveen S, A Shahzad, S Saema (2010). In vitro plant regeneration system for Cassia siamea Lam., a leguminous tree of economic importance. Agrofor Syst 80:109-116

Rai MK, M Phulwaria, AK Gupta, NS Shekhawat, U Jaiswal (2012). Genetic homogeneity of guava plants derived from somatic embryogenesis using SSR and ISSR markers. Plant Cell Tiss Org Cult 111:259-264

Raju CS, A Aslam, A Shajahan (2015). High-efficiency direct somatic embryogenesis and plant regeneration from leaf base explants of turmeric (Curcuma longa L.). Plant Cell Tiss Org Cult 122:79-87

Rehman SU, K Choe, HH Yoo (2016). Review on a traditional herbal medicine, Eurycoma longifolia Jack (Tongkat Ali): Its traditional uses, chemistry, evidence-based pharmacology and toxicology. Molecules 21; Article 331

Rodziah K, MN Madihah (2015). Thidiazuron induces high frequency direct somatic embryogenesis growth from cotyledon culture of Eurycoma longifolia. Sains Malays 44:913-920

Rohela GK, P Jogam, P Bylla, C Reuben (2019). Indirect regeneration and assessment of genetic fidelity of acclimated plantlets by SCoT, ISSR, and RAPD markers in Rauwolfia tetraphylla L.: An endangered medicinal plant. BioMed Res Intl 2019; Article 3698742
Sharafi AA, AA Abkenar, A Sharafi, M Masaeli (2016). Genetic variation assessment of acid lime accessions collected from south of Iran using SSR and ISSR molecular markers. Physiol Mol Biol Plants 22:87-95

Shekhawat MS, N Kannan, M Manokari CP Ravindran (2015). In vitro regeneration of shoots and ex vitro rooting of an important medicinal plant Passiflora foetida L. through nodal segment cultures. J Genet Eng Biotechnol 13:209-214

Shekhawat MS, N Kannan, M Manokari, MP Ramanujam (2014). An efficient micropropagation protocol for high-frequency plantlet regeneration from liquid culture of nodal tissues in a medicinal plant Turnera ulmifolia L. J Sustain For 33:327-336

Sidorov VA (2013). Plant tissue culture in biotechnology: Recent advances in transformation through somatic embryogenesis. Biotechnol Acta 6:118-131

Singh CK, SR Raj, VR Patil, PS Jaiswal, N Subhash (2013). Plant regeneration from leaf explants of mature sandalwood (Santalum album L.) trees under in vitro conditions. In Vitro Cell Dev Biol Plant 49:216-222

Srikun N (2017). In vitro propagation of the aromatic herb Strobilanthes tonkinensis Lindau. Agric Nat Resour 51:15-19

Tnah LH, CT Lee, SL Lee, KKS Ng, CH Ng, SS Hwang (2011) Microsatellite markers of an important medicinal plant, Eurycoma longifolia (Simaroubaceae), for DNA profiling. Amer J Bot 98:130-132

Toppo DD, G Singh, DK Purshottam, P Misra (2012). Improved in vitro rooting and acclimatization of Jatropha curcas plantlets. Biomass Bioener 44:42-46

Vieira MLC, L Santini, AL Diniz, CDF Munhoz (2016). Microsatellite markers: What they mean and why they are so useful. Genet Mol Biol 39:312-328

Wang YJ, XY Li, J Han, WM Fang, XD Li, SS Wang, JG Fang (2011). Analysis of genetic relationships and identification of flowering-mei cultivars using EST-SSR markers developed from apricot and fruiting-mei. Sci Hortic 132:12-17

Yahya MF, NH Hassan, N Abdullah, SSA Rahman, H Ismail, MZ Abdullah, FFM Ariff, M L Ngah, R Koter, R Khalid, R Abdullah (2015). Acclimatization of Eurycoma longifolia (Tongkat Ali) plantlets to ex vitro conditions. J Trop Resour Sustain Sci 3:129-131 